\title{
Does a change in iris diameter indicate heart rate variability?
}

\author{
Şahbender Koç¹, Sadettin Selçuk Baysal ${ }^{2}$, Kerem Özbek ${ }^{2 *}$ \\ ${ }^{1}$ Cardiologist and Ophtalmologist, Keçiören Training and Research Hospital,Ankara, Turkey \\ ${ }^{2}$ Cardiologist, Mehmet Akif Inan Training and Research Hospital,Şanlıurfa, Turkey
}

\begin{abstract}
The existence of the retinohypothalamic pathway suggests that light may influence autonomic outflow activity. The objective of this study was to examine the correlation between the estimated iris muscle sympathetic-parasympathetic area (IRIS) ratio and the sympathetic-parasympathetic ratio (Low Frequency (LF)/High Frequency (HF) ratio). The study population consisted of 200 females and 200 males (mean age, $32.4 \pm 7.1 \mathrm{y}$ ). The IRIS ratio was determined from digital photographs of the iris in a computer setting. The $\mathrm{LF} / \mathrm{HF}$ ratio was determined from records of heart rate variability obtained using a Holter implementation. The minimum LF/HF ratio was 1.4 and the maximum 5.6 (mean, 3.0 \pm 0.8 ). The minimum IRIS ratio was 1.4 and the maximum 4.9 (mean, $2.7 \pm 0.6$ ). A strong positive correlation was determined between the LF/HF and IRIS ratios in the entire population $(r=0.825 ; p<0.001)$ and positive correlations were also observed in males and females separately. The intraclass correlation between the LF/HF and IRIS ratios was 0.836 . A strong correlation exists between the LF/HF and IRIS ratios.
\end{abstract}

Keywords: Sympathetic parasympathetic ratio, Iris collarette, Autonomous nervous system.

Accepted on January 18, 2018

\section{Introduction}

The iris is the only tissue in which simultaneous interactions among smooth muscles stimulated by sympathetic and parasympathetic nerves can be observed with the naked eye [1]. The iris contains the neural crest, which is comprised of the Autonomous Nervous System (ANS) and dorsal root ganglia [2]. Fibers from the hypothalamus join the parasympathetic system through the dorsal longitudinal fasciculus and the medial forebrain bundle and unite with the Edinger-Westphal nucleus or the lateral horns of the thoracic spinal cord [3]. A portion of these parasympathetic fibers innervate the constrictor muscle fibers of collarette and limit the iris pupil via the oculomotor nerve. The hypothalamus is the major control and integration center of the ANS. The sympathetic nerves emerging from the hypothalamus extend along the length of the carotid artery synapse with the superior cervical ganglion and subsequently innervate the mydriasis muscle fibers beneath the iris collarette and iris root [3].

Heart Rate Variability (HRV) refers to changes in the time interval between heartbeats and is regulated by the ANS [4]. Sympathetic and parasympathetic activities can be determined at certain sensitivity by HRV assessment using Low Frequency (LF) and High Frequency (HF) measurements [4]. Previous epidemiological studies have shown that HRV is associated with both cardiac and non-cardiac all-cause mortality [5].
The objective of the study was to determine the estimated iris muscle area (IRIS) ratio of iris muscles innervated by parasympathetic and sympathetic nerves and its relationship with HRV, which is an ANS indicator of the heart.

\section{Materials and Methods}

A total of 400 healthy volunteers (200 males and 200 females) with brown eyes were included in the study. We enrolled apparently healthy subjects who had no history of diabetes mellitus, hypertension, coronary artery disease, heart failure, cigarette smoking, eye disease, psychological illness, or drug therapy affecting the ANS.

A three-channel standard ambulatory Holter recording system (DMS Software Cardioscan II Holter monitoring system, ver. 11.4.0054a) was used to measure the pulse rate by HRV frequency domain analysis after removing the artefacts. The LF (0.04-0.15 Hz) and HF (0.16-0.4 Hz) ratings were recorded for $24 \mathrm{~h}$ (day and night average) [6].

Photographs of both irises of the healthy volunteers were taken using a digital camera (5-megapixel camera, $1.75 \mu \mathrm{m}$ pixels, $0.5 \mathrm{X}$ digital zoom, LED flash) in the same room in daylight, at the same time of day with the same flash. Patients with nonspecific and interrupted collarette (peripupillar ring) limits were not included in the study. An image software program was used to draw circular limits over the Iris Exterior Circle (IEC), Collarette Circle (CC), and Pupil Circle (PC) on digital 
photographs. The areas between the circles were measured. IEC-PC refers to the estimated total area of the dilator plus constrictor muscles stimulated sympathetically and parasympathetically; CC-PC refers to the estimated area stimulated parasympathetically; and (IEC-PC)-(CC-PC) refers to the estimated area stimulated sympathetically. The likelihood that the IRIS ratio was equal to the LF/HF ratio was calculated using the formula (IEC-PC)-)CC-PC)/(CC-PC). The average of three measurements was calculated for each photograph (Figure 1) [7].

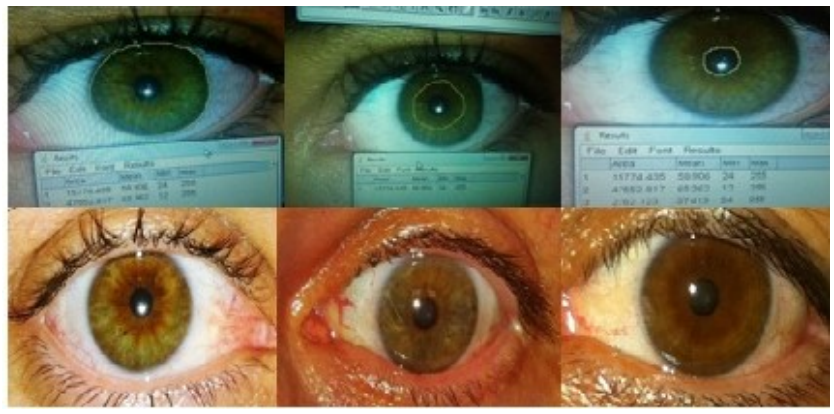

Figure 1. Measurement of the IRIS ratio using image software.

The statistical analyses were carried out using SPSS for Windows 22 (IBM SPSS Inc., Chicago, IL, USA). The normality of the data distribution was assessed using the Kolmogorov-Smirnov test. Numerical variables with a normal distribution are presented as means \pm standard deviation, while those with a non-normal distribution are presented as medians (range). The t-test (for numerical variables displaying a normal distribution) and Mann-Whitney U-test (for numerical variables displaying an abnormal distribution) were used to determine differences between two independent groups. The association between the numerical parameters was determined by Pearson and Spearman correlation analyses. The BlandAltman analysis was used to assess differences in compliance of the IRIS ratio and the $\mathrm{LF} / \mathrm{HF}$ ratio in terms of ICC. A pvalue $<0.05$ was considered significant.

Studies were carried out in compliance with the Declaration of Helsinki after obtaining approval from the ethics committee. Informed consent was obtained from all subjects prior to participation.

\section{Results}

The study population consisted of 200 females and 200 males (mean age, $32.4 \pm 7.1 \mathrm{y})$. Heart rate $(71.9 \pm 16.8 \mathrm{bpm})$, Systolic Blood Pressure (SBP)/Diastolic Blood Pressure (DBP) $(104.4 \pm 11.4 / 70.0 \pm 10.4 \mathrm{mmHg})$ and Body Mass Index (BMI) $\left(19.2 \pm 2.8 \mathrm{~kg} / \mathrm{m}^{2}\right)$ were all within the normal ranges. Age, BMI, SBP, DBP, heart rate, and levels of glucose, creatinine, hemoglobin, LDL, thyroid stimulating hormone, and leukocytes did not differ significantly by sex. The mean LF/HF ratio was $3.0 \pm 0.8$ (range, 1.4-5.6). The mean IRIS ratio was $2.7 \pm 0.6$ (range, 1.4-4.9). The LF/HF and IRIS ratios were significantly higher in female than male patients $(3.3 \pm 0.8 \mathrm{vs}$. $2.8 \pm 0.7, \mathrm{p}<0.001 ; 2.8 \pm 0.7$ vs. $2.5 \pm 0.5, \mathrm{p}<0.001$, respectively) (Table 1 ).

A strong correlation was observed between the LF/HF and IRIS ratios in the entire population $(\mathrm{r}=0.825 ; \mathrm{p}<0.001)$, and the correlation remained when evaluated in males and females separately (Figure 2). A correlation was detected between age and the LF/HF ratio in the entire population as well as in males and females individually. No association was observed between any of the other variables and the LF/HF ratio (Table 2).

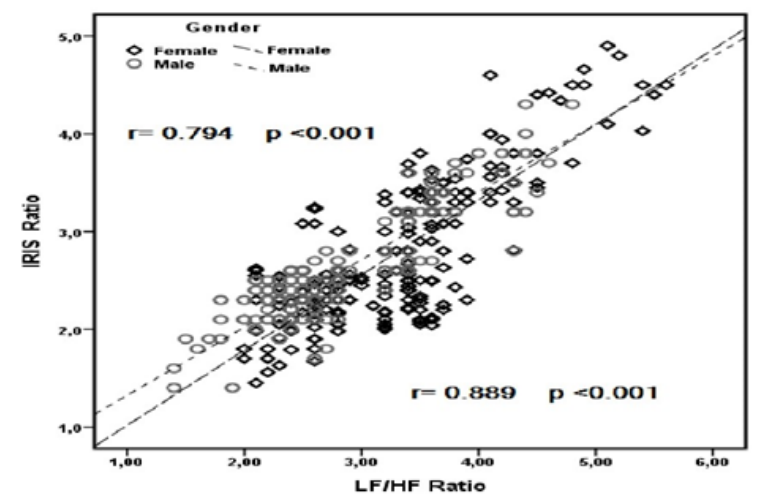

Figure 2. The association between the IRIS ratio and LF/HF ratio.

A correlation was evident between age and the IRIS ratio in the entire population and in males and females individually. No association was identified between any of the other variables and the LF/HF ratio (Table 3). The ICC between the LF/HF and IRIS ratios was 0.836 .

The bias between the LF/HF and IRIS ratios determined by Bland-Altman plots was 0.37 , with a standard deviation of 0.43 and $95 \%$ confidence interval of -0.48 to 1.22 (Figure 3 ).

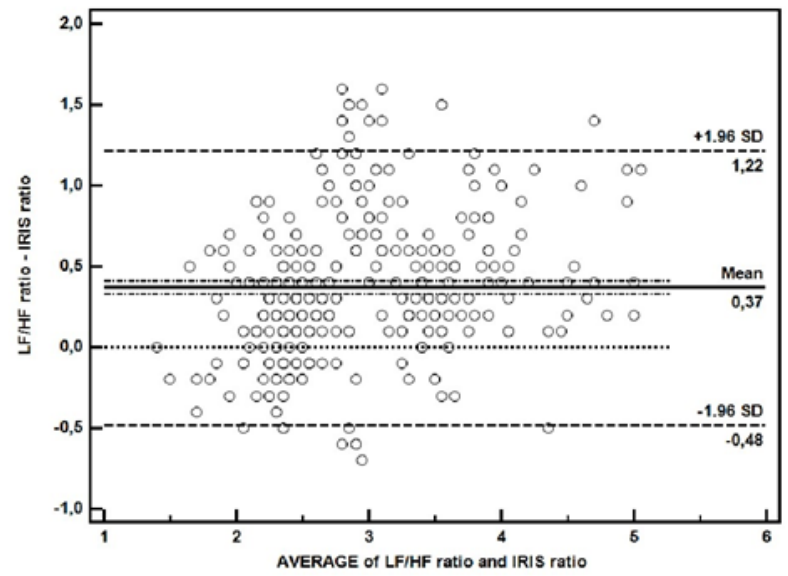

Figure 3. Analysis of the $L F / H F$ and IRIS ratio measurements using Bland-Altman plots.

Table 1. Demographic and clinical characteristics of the patients. 


\begin{tabular}{|c|c|c|c|c|}
\hline \multirow[t]{2}{*}{ Variables } & All & Females & Males & \multirow[t]{2}{*}{$p$-value } \\
\hline & $n=400$ & $\mathbf{n}=\mathbf{2 0 0}$ & $\mathbf{n}=\mathbf{2 0 0}$ & \\
\hline Age $(y)$ & $32.4 \pm 7.1$ & $32.8 \pm 6.3$ & $32.0 \pm 7.8$ & 0.26 \\
\hline BMI $\left(\mathrm{kg} / \mathrm{m}^{2}\right)$ & $19.2 \pm 2.8$ & $19.4 \pm 3.1$ & $19.0 \pm 2.5$ & 0.177 \\
\hline $\mathrm{SBP}(\mathrm{mmHg})$ & $104.4 \pm 11.4$ & $104.7 \pm 10.9$ & $104.1 \pm 11.9$ & 0.631 \\
\hline $\mathrm{DBP}(\mathrm{mmHg})$ & $70.0 \pm 10.4$ & $69.8 \pm 9.7$ & $70.1 \pm 11.1$ & 0.795 \\
\hline Heart rate $(\mathrm{bpm})$ & $71.9 \pm 16.8$ & $72.7 \pm 16.5$ & $71.2 \pm 17.1$ & 0.355 \\
\hline Glucose (mg/dl) & $83.2 \pm 12.6$ & $82.6 \pm 13.6$ & $83.8 \pm 11.4$ & 0.318 \\
\hline Creatinine $(\mathrm{mg} / \mathrm{dl})$ & $0.85 \pm 0.21$ & $0.84 \pm 0.21$ & $0.86 \pm 0.21$ & 0.451 \\
\hline Hemoglobin (gr/dl) & $12.6 \pm 2.0$ & $12.6 \pm 2.0$ & $12.6 \pm 2.1$ & 0.888 \\
\hline $\mathrm{LDL}(\mathrm{mg} / \mathrm{dl})$ & $94.9 \pm 21.4$ & $95.1 \pm 22.3$ & $94.6 \pm 0.6$ & 0.81 \\
\hline TSH (mIU/l) & $1.3(0.14-4.90)$ & $1.2(0.14-4.80)$ & $1.4(0.18-4.90)$ & 0.146 \\
\hline Leukocytes $\left(/ \mathrm{mm}^{3}\right)$ & $7.100 \pm 1.400$ & $7.100 \pm 1.400$ & $7.200 \pm 1.400$ & 0.326 \\
\hline LF/HF ratio & $3.0 \pm 0.8$ & $3.3 \pm 0.8$ & $2.8 \pm 0.7$ & $<0.001$ \\
\hline IRIS ratio & $2.7 \pm 0.6$ & $2.8 \pm 0.7$ & $2.5 \pm 0.5$ & $<0.001$ \\
\hline
\end{tabular}

BMI: Body Mass Index; DBP: Diastolic Blood Pressure; LDL: Low Density Lipoprotein; SBP: Systolic Blood Pressure; TSH: Thyroid Stimulating Hormone; Values represent means \pm standard deviation or medians (range). Data in bold are significant.

Table 2. Variables associated with the LF/HF ratio.

\begin{tabular}{|c|c|c|c|c|c|c|}
\hline \multirow[t]{3}{*}{ Variables } & \multicolumn{6}{|c|}{ LF/HF ratio } \\
\hline & \multicolumn{2}{|c|}{ Entire population } & \multicolumn{2}{|l|}{ Female } & \multicolumn{2}{|l|}{ Male } \\
\hline & $r$ & p & $r$ & p & $r$ & $\mathbf{P}$ \\
\hline IRIS ratio & 0.825 & $<0.001$ & 0.794 & $<0.001$ & 0.889 & $<0.001$ \\
\hline Age (y) & 0.267 & 0.001 & 0.051 & 0.474 & 0.221 & 0.002 \\
\hline BMI $\left(\mathrm{kg} / \mathrm{m}^{2}\right)$ & -0.027 & 0.597 & -0.049 & 0.235 & 0.081 & 0.256 \\
\hline $\mathrm{SBP}(\mathrm{mmHg})$ & -0.033 & 0.516 & -0.042 & 0.558 & -0.047 & 0.513 \\
\hline $\mathrm{DBP}(\mathrm{mmHg})$ & -0.078 & 0.12 & -0.046 & 0.514 & -0.111 & 0.118 \\
\hline Heart rate $(\mathrm{bpm})$ & 0.021 & 0.672 & -0.045 & 0.53 & 0.059 & 0.405 \\
\hline Glucose (mg/dl) & 0.038 & 0.447 & 0.078 & 0.269 & 0.034 & 0.628 \\
\hline Creatinine $(\mathrm{mg} / \mathrm{dl})$ & -0.004 & 0.935 & 0.034 & 0.63 & -0.018 & 0.8 \\
\hline Hemoglobin (g/dl) & -0.028 & 0.58 & 0.098 & 0.168 & -0.178 & 0.112 \\
\hline LDL (mg/dl) & 0.059 & 0.235 & -0.014 & 0.848 & 0.148 & 0.137 \\
\hline TSH (mIU/l) & -0.034 & 0.504 & -0.015 & 0.835 & -0.062 & 0.383 \\
\hline Leukocytes(/mm3) & 0.031 & 0.541 & 0.048 & 0.495 & 0.055 & 0.441 \\
\hline
\end{tabular}

BMI: Body Mass Index $\left(\mathrm{kg} / \mathrm{m}^{2}\right)$; SBP: Systolic Blood Pressure $(\mathrm{mmHg})$; DBP: Diastolic Blood Pressure $(\mathrm{mmHg})$; LDL: Low Density Lipoprotein (mg/dl); TSH: Thyroid Stimulating Hormone (mIU/l); r=correlation coefficient. Data in bold are significant.

Table 3. Variables associated with the IRIS ratio.

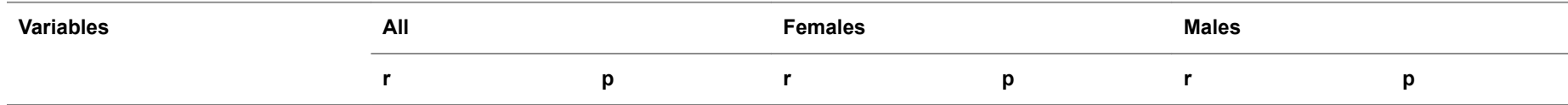




\begin{tabular}{|c|c|c|c|c|c|c|}
\hline Age $(y)$ & 0.232 & 0.008 & 0.04 & 0.577 & 0.208 & 0.003 \\
\hline BMI $\left(\mathrm{kg} / \mathrm{m}^{2}\right)$ & 0.03 & 0.547 & -0.011 & 0.877 & 0.069 & 0.33 \\
\hline $\mathrm{SBP}(\mathrm{mmHg})$ & -0.029 & 0.564 & 0.058 & 0.413 & 0.016 & 0.826 \\
\hline $\mathrm{DBP}(\mathrm{mmHg})$ & -0.065 & 0.196 & 0.11 & 0.121 & -0.011 & 0.881 \\
\hline Heart rate $(\mathrm{bpm})$ & 0.052 & 0.296 & 0.012 & 0.867 & 0.09 & 0.205 \\
\hline Glucose (mg/dl) & 0.041 & 0.413 & 0.088 & 0.216 & -0.009 & 0.895 \\
\hline Creatinine $(\mathrm{mg} / \mathrm{dl})$ & -0.033 & 0.515 & -0.018 & 0.801 & -0.038 & 0.589 \\
\hline Hemoglobin (gr/l) & -0.029 & 0.558 & 0.083 & 0.242 & -0.191 & 0.107 \\
\hline LDL (mg/dl) & 0.027 & 0.587 & -0.049 & 0.494 & 0.138 & 0.151 \\
\hline TSH (mIU/l) & -0.069 & 0.17 & -0.053 & 0.46 & -0.099 & 0.165 \\
\hline Leukocytes $\left(/ \mathrm{mm}^{3}\right)$ & 0.075 & 0.135 & 0.137 & 0.053 & 0.017 & 0.817 \\
\hline
\end{tabular}

BMI: Body Mass Index $\left(\mathrm{kg} / \mathrm{m}^{2}\right)$; SBP: Systolic Blood Pressure (mmHg); DBP: Diastolic Blood Pressure (mmHg); LDL: Low Density Lipoprotein (mg/dl); TSH: Thyroid Stimulating Hormone (mIU/l); r=correlation coefficient. Data in bold are significant.

\section{Discussion}

The iris pupil is opened and closed via a single constrictor or dilator muscle. The ANS is activated when we open our eyes, and the amount of light is adjusted by the iris [8]. Non-visual impacts of light are mediated by melanopsin-based photoreceptors in the retinal photosensitive ganglia cells [9]. Melanopsin is also found in the melanophores of the iris and inner brain [10]. Photosensitive retinal ganglion cells transmit light stimuli to the suprachiasmatic nucleus ( $\mathrm{SCN}$; circadian center) via the retinohypothalamic tract. In the dark, melatonin released rhythmically from the pineal gland also strongly affects SCN neuronal activity [10]. This area receives stimulation from the visual photoreceptor system and from various areas of the brain, including the brain stem, limbic system, and cerebral cortex and contains multiple synapses with the pineal gland. The input of light into the retina, which is adjusted by the iris, is associated with the areas of the brain that regulate the ANS. Light may cause acute physiological effects such as rapid melatonin suppression, increased alertness, and increased heart rate and sympathetic nerve tonus [11].

The anterior cingulate cortex, amygdala, parabrachial nucleus, hypothalamus, periaqueductal grey matter, anterior insula, and some areas of the medulla play significant roles in the regulation of cardiac function. These cerebral structures are associated with cardiac activity via the sympathetic and parasympathetic nervous systems [12].

In this study, a good correlation was observed between the IRIS and LF/HF ratios. In a small study of 44 healthy volunteers, Okutucu et al. showed that computerized dynamic pupillometry results were correlated with HRV parameters [13]. In another small study, HRV, blood pressure variability, baroreflex function, and light reaction pupillography parameters of 50 individuals were analysed, and only HRV was associated with pupil diameter [14]. Another study involving 41 well-trained male athletes found that pupillometry was associated with HRV, and physical fitness affected autonomic regulation of the pupillary light reflex [15]. In contrast, Billman reported that the LF/HF ratio was weakly associated with parasympathetic and sympathetic nervous system activities. The $\mathrm{LF} / \mathrm{HF}$ ratio, particularly LF, is affected by respiration. In many physiological situations, LF/HF data are insufficient to quantify cardiac "sympatho-vagal balance" accurately, either in a healthy or disease state [16].

The correlation between pupil diameter and HRV has also been investigated in some diseases concomitant with an ANS disorder. Parkinson's disease (PD) is accompanied by ANS dysfunction and neurodegenerative changes. Jain et al. demonstrated simultaneous ANS dysfunction in both pupillary diameter and in cardiac system via HRV patients with PD [17]. Similarly, the pupil function is affected in schizophrenia, which has previously been shown to be accompanied by cardiac autonomic dysfunction, but may be proportional to the severity of the schizophrenia [18]. In a comparative study of 36 type 2 diabetic patients and 36 healthy subjects, pupil diameter was associated with diabetic autonomic neuropathy; however, it was not associated with cardiac autonomic dysfunction [19].

In conclusion, we identified a relationship between the IRIS ratio and HRV in 400 healthy subjects and demonstrated cardiac autonomic function. The IRIS ratio can also be applied to diseases accompanied by cardiac autonomic dysfunction. However, further studies are needed to demonstrate a relationship between the IRIS ratio and HRV in patients with cardiac disease.

\section{Acknowledgements}

This research received no grant from any funding agency in the public, commercial, or not-for-profit sectors. The authors declare no conflicts of interest. 


\section{References}

1. Onorati F, Mainardi LT, Sirca F, Russo V, Barbieri R. Nonlinear analysis of pupillary dynamics. Biomedizinische Technik Biomed Eng 2016; 61: 95-106.

2. Onorati F, Barbieri R, Mauri M, Russo V, Mainardi L. Reconstruction and analysis of the pupil dilation signal: application to a psychophysiological affective protocol. Conference proceedings: Annual International Conference of the IEEE Engineering in Medicine and Biology Society IEEE Engineering in Medicine and Biology Society Annual Conference 2013; 2013: 5-8.

3. Dos Santos Junior ED, Da Silva AV, Da Silva KR, Haemmerle CA, Batagello DS, Da Silva JM. The centrally projecting Edinger-Westphal nucleus-I: Efferents in the rat brain. J Chem Neuroanat 2015; 68: 22-38.

4. Laborde S, Mosley E, Thayer JF. Heart rate variability and cardiac vagal tone in psychophysiological researchrecommendations for experiment planning, data analysis, and data reporting. Front Psychol 2017; 8: 213.

5. Gillum RF, Makuc DM, Feldman JJ. Pulse rate, coronary heart disease, and death: the NHANES I epidemiologic follow-up study. Am Heart J 1991; 121: 172-177.

6. Heart rate variability: standards of measurement, physiological interpretation and clinical use. Task Force of the European Society of Cardiology and the North American Society of Pacing and Electrophysiology. Circulation 1996; 93: 1043-1065.

7. Lee JC, Kim JE, Park KM, Khang G. Evaluation of the methods for pupil size estimation: on the perspective of autonomic activity. Conference proceedings: Annual International Conference of the IEEE Engineering in Medicine and Biology Society IEEE Engineering in Medicine and Biology Society Annual Conference 2004; 2: 1501-1504.

8. Yasukouchi A, Ishibashi K. Non-visual effects of the color temperature of fluorescent lamps on physiological aspects in humans. J Physiol Anthropol Appl Human Sci 2005; 24: 41-43.

9. Brainard GC, Rollag MD, Hanifin JP. Photic regulation of melatonin in humans: ocular and neural signal transduction. J Biol Rhythms 1997; 12: 537-546.

10. Peirson SN, Halford S, Foster RG. The evolution of irradiance detection: melanopsin and the non-visual opsins. Philosop Trans Royal Soc London Biol Sci 2009; 364: 2849-2465.
11. Vandewalle G, Maquet P, Dijk DJ. Light as a modulator of cognitive brain function. Trends Cogn Sci 2009; 13: 429-438.

12. Palma JA, Benarroch EE. Neural control of the heart: recent concepts and clinical correlations. Neurology 2014; 83: 261-271.

13. Okutucu S, Civelekler M, Aparci M, Sabanoglu C, Dikmetas O, Aksoy H. Computerized dynamic pupillometry indices mirrors the heart rate variability parameters. Eur Rev Med Pharmacol Sci 2016; 20: 2099-2105.

14. Bar KJ, Schulz S, Koschke M, Harzendorf C, Gayde S, Berg W. Correlations between the autonomic modulation of heart rate, blood pressure and the pupillary light reflex in healthy subjects. J Neurol Sci 2009; 279: 9-13.

15. Kaltsatou A, Kouidi E, Fotiou D, Deligiannis P. The use of pupillometry in the assessment of cardiac autonomic function in elite different type trained athletes. Eur J Appl Physiol 2011; 111: 2079-2087.

16. Billman GE. The $\mathrm{LF} / \mathrm{HF}$ ratio does not accurately measure cardiac sympatho-vagal balance. Front Physiol 2013; 4: 26.

17. Jain S, Siegle GJ, Gu C, Moore CG, Ivanco LS, Jennings JR. Autonomic insufficiency in pupillary and cardiovascular systems in Parkinsons disease. Parkinson Related Disord 2011; 17: 119-122.

18. Bar KJ, Boettger MK, Schulz S, Harzendorf C, Agelink MW, Yeragani VK. The interaction between pupil function and cardiovascular regulation in patients with acute schizophrenia. J Int Feder Clin Neurophysiol 2008; 119: 2209-2213.

19. Dutsch M, Marthol H, Michelson G, Neundorfer B, Hilz MJ. Pupillography refines the diagnosis of diabetic autonomic neuropathy. J Neurol Sci 2004; 222: 75-81.

\section{*Correspondence to}

\section{Kerem Özbek}

Department of Cardiology

Mehmet Akif Inan Training and Research Hospital

Turkey 